\title{
Correction to: Animal manure rhizobacteria co-fertilization suppresses phytonematodes and enhances plant production: evidence from field and greenhouse
}

\author{
Abdelhadi A. I. Ali ${ }^{1} \cdot \operatorname{Ramadan}$ M. El-Ashry ${ }^{1} \cdot$ Ahmed A. A. Aioub $^{1}$ (1)
}

Published online: 2 December 2021

(c) Deutsche Phytomedizinische Gesellschaft 2021

\section{Correction to: Journal of Plant Diseases and Protection} https://doi.org/10.1007/s41348-021-00529-9

In the original publication of the article, the caption of Fig. 1 has been replaced with the caption of Fig. 2. This has been corrected in this paper (Figs. 1 and 2).

Fig. 1 Map for the site description of nematode farm level survey in Egypt
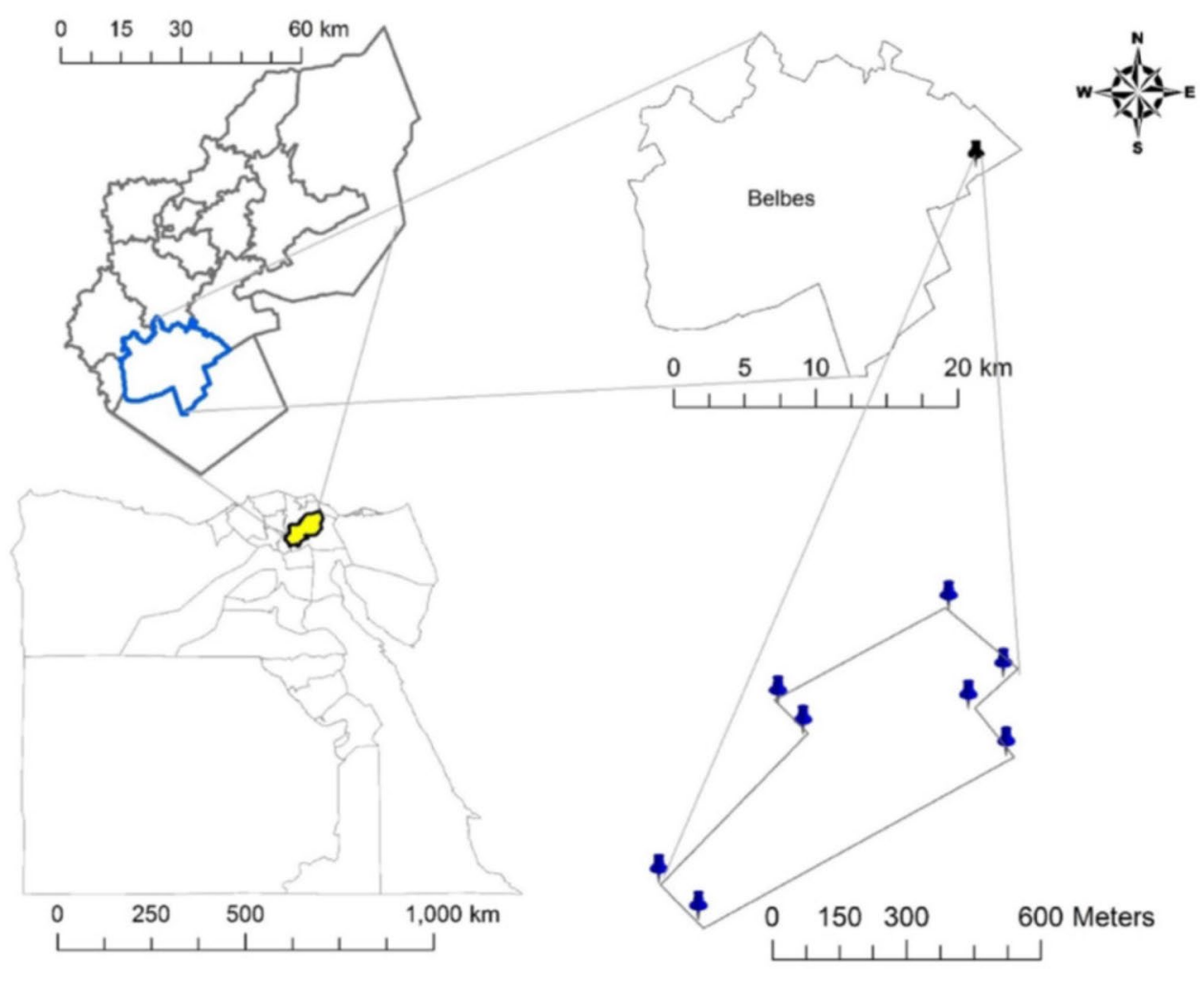

The original article can be found online at https://doi.org/10.1007/ s41348-021-00529-9.

Ahmed A. A. Aioub

ahmedaioub1991@gmail.com; a.aioub@zu.edu.eg

1 Plant Protection Department, Faculty of Agriculture,

Zagazig University, Zagazig 44511, Egypt 
Fig. 2 Changes of the communities of order nematode genera sorted in descending by a frequency of occurrence (FO), b population density (PD), and c prominence value $(\mathrm{PV})$
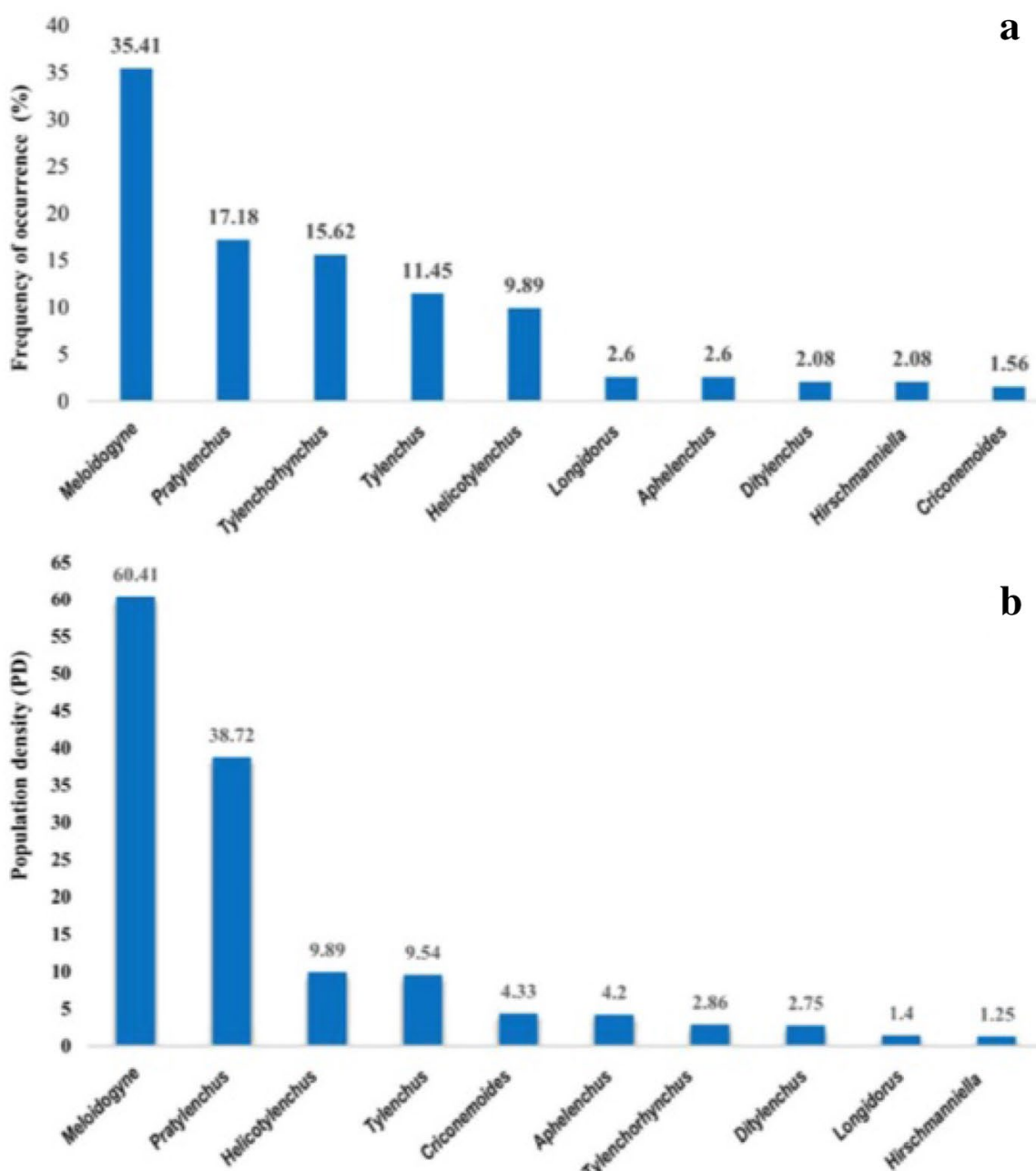

b

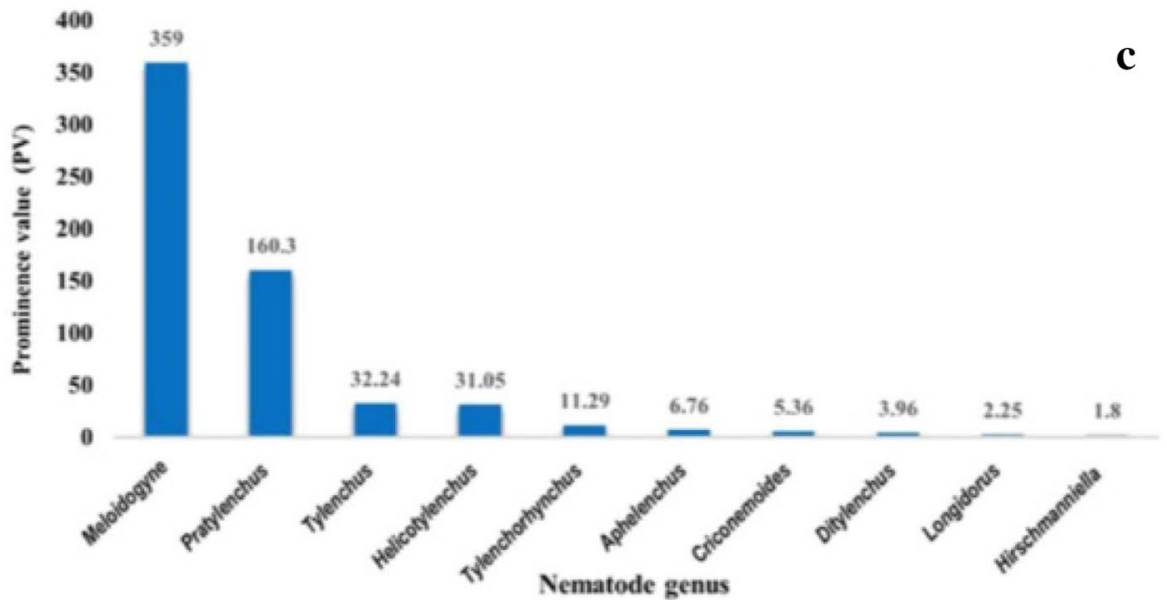

Publisher's Note Springer Nature remains neutral with regard to jurisdictional claims in published maps and institutional affiliations. 